\title{
Shape Change According to the Mixing of Forward and Rear Slope Slice Lines in Graduation Haircuts
}

\author{
Seon-Mi Jang, Won-Ji Jung* \\ Department of Beauty Science, Kwangju Women's University, Gwangju, Korea
}

\author{
"Corresponding author: Won-Ji Jung, \\ Department of Beauty Science, Kwangju \\ Women's University, 201 Yeodae Gil, \\ Gwangsangu, Gwangju 62396, Korea \\ Tel.: +8262950 3798 \\ Fax: +82 629503797 \\ Email: jwj65@hanmail.net
}

Received July 8, 2019

Revised August 8, 2019

Accepted September 3, 2019

Published September 30, 2019

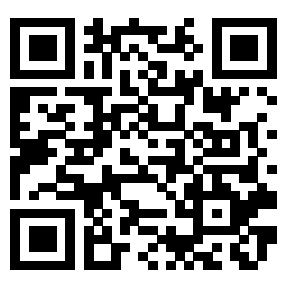

\begin{abstract}
Purpose: This study aims to provide basic data on haircut styles by demonstrating the variation in styles and hair lengths on combining the forward slope slice line at the back of the head and the rear slope slice line on the sides of the head for graduation haircuts. Method: An experimenter cut a mannequin's hair by applying the slice lines MS1 $\left(40^{\circ}\right)$, MS2 $\left(55^{\circ}\right)$, and MS3 $\left(70^{\circ}\right)$ for a low graduation cut of approximately $30^{\circ}$, medium graduation cut of approximately $45^{\circ}$, and high graduation cut of approximately $70^{\circ}$, respectively. Results: Various shape lines were formed based on each slice line combined with each type of graduation haircuts. The haircut style using MS1 combined with the medium graduation haircut resulted in the most effective volume. Conclusion: The results have demonstrated that the slice lines that were combined with graduation cuts can be used to change the shape lines and shapes of haircut styles. These results suggest that a variety of haircut designs can be created by using a mix of forward and rear slope slice lines.
\end{abstract}

Keywords: Graduation haircut, Rear slope slice line, Forward slope slice line, Haircut, Combined slice lines

\section{Introduction}

현대의 뷰티 트랜드(beauty trend)는 매스 미디어의 발달로 빠 르게 변화하고 있으며 대중은 미를 통해 자신의 개성과 이미지를 표현한다. 헤어스타일은 이미지를 변화시키는 요소로써 크게 작용 하여 개성을 표현하는 수단이 된다. 그리고 인간이 가지고 있는 모 발이라는 소재의 특수성은 미를 표현하는데 있어서 획일화 되지 않은 본연의 개성을 표현할 수 있게 한다(Hong \& Joo, 2015).

헤어스타일을 만들어내는 헤어미용은 개인의 개성과 아름다움 을 만족시키는 행위예술이며 창조의 결과물이다(Kim, 2017). 헤 어커트(haircut)는 헤어스타일을 만드는 기초이며 모든 시술에 토 대가 되기 때문에 헤어디자인에서 그 중요성과 비중이 크다(Jung $\&$ Youn, 2008).

국가직무능력표준(National Competency Standard, NCS)에 서 헤어 미용의 학습 모듈은 기초 헤어커트를 원랭스 커트(onelength cut), 그래주에이션 커트(graduation cut), 레이어 커트 (layer cut)로 분류하고 있다. 그리고 Jung (2016)은 그래주에이
션 커트를 로우 그래주에이션(low graduation), 미디엄 그래주에 이션(medium graduation), 하이 그래주에이션(high graduation) 으로 구분하여 제시하였다.

그래주에이션 커트는 머리의 아래쪽이 가장 짧고 위로 올라가 면서 점점 길어지며 비교적 적은 단차를 주는 커트 방법을 말한 다. 커트를 하고 난 후 볼륨의 위치와 정도에 따라서 두상의 단 점을 보완할 수 있고 장점을 부각시킬 수 있기 때문에 동양인의 납작한 후두부와 각진 얼굴형에 효과적이라고 할 수 있다(Kim, 2015). 그리고 그래주에이션 커트는 패턴(pattern)에 따라서도 평 행 그래주에이션 커트(parallel graduation cut), 증가 그래주에 이션 커트(increasing graduation cut), 감소 그래주에이션 커트 (decreasing graduation cut)로 나눌 수 있는데, 이것은 슬라이 스 라인(slice line)에 따라서 변화되는 커트 형태를 분류한 것이다 (Kim et al., 2018). 그래주에이션 커트는 시술각도뿐만 아니라 길이와 베이스(base), 파팅(parting), 섹션(section)의 조합으로도 다양한 디자인연출이 가능하며 손가락의 위치가 평행인지 비평행 인지에 따라 형태선이 변화하여 디자이너의 감각적인 표현이 가능 
하다(Hong \& Joo, 2015).

헤어커트에서 슬라이스 라인은 커트를 편리하게 진행하기 위해 시술자가 원하는 디자인에 따라 블로킹(blocking)을 더 작게 분할 하는 것을 말한다(Kim \& Lee, 2017). 섹션(section)분할의 과정 은 시술자가 원하는 헤어 디자인(hair design)을 연출하기 위해 두 상에 라인을 그리는 작업으로 사전에 결정해야 한다(Park \& Seo, 2009).

헤어커트에 관한 선행연구로는 Ha \& Youn (2017)이 한국형 헤 어커트 방법에 대한 연구를 하여 보고하였고, Han \& Youn (2007) 이 오버다이렉션을 중심으로 피타고라스 정리를 이용한 헤어커 트의 라인에 대한 분석을 연구하여 발표하였다. Jung \& Youn (2015)은 헤어커트의 형태에 변화를 주는 요인에 관한 연구를 보
고 하였는데, 그 요인은 길이, 슬라이스 라인, 베이스, 시술각도라 는 결과를 도출하였다. $\operatorname{Kim}$ (2016)은 커트 블럭의 량과 모발의 길 이, 섹션 라인의 변화에 따른 헤어스타일의 형태 변화를 원랭스 커 트와 인크리스 레이어 커트를 중심으로 연구하여 보고하였다.

섹션과 시술각도에 관한 연구 또한 이루어졌는데, 원랭스 커 트 시 슬라이스 라인 기울기에 따른 형태선과 길이 변화를 Moon \& Jung (2018)이 보고하였다. Jung \& Kim (2017)은 이사도라 보브형 커트와 그래주에이션 커트를 혼합해서 커트의 다양한 스 타일을 보여주었고 Jung \& Youn (2014)은 헤어커트 시 평행선 (parallel Line)에서의 형태변화를 모발길이, 시술각도, 베이스를 중심으로 연구하였다.

Song \& Cho (2012)는 상고 유형의 남성 헤어커트에서 연결

Table 1. Expanded table on varieties of low graduation cut according to the mix of slice lines

\begin{tabular}{lcc}
\hline Shape & Low graduation cut \\
Length & Back & N.P $\mathrm{cm}$ \\
Direction & Side & Forward slope \\
Slice line & & Rear slope \\
Base & MS1, MS2, MS3 \\
Angle & Not applicable \\
\hline
\end{tabular}

N.P, nape point; MS, mixed slice line which mixed forward slope line and rear slope line.

Table 2. Results of performing a low graduation cut with a mix of slice lines

MS1 Low graduation cut

N.P, nape point; MS, mixed slice line which mixed forward slope line and rear slope line. 

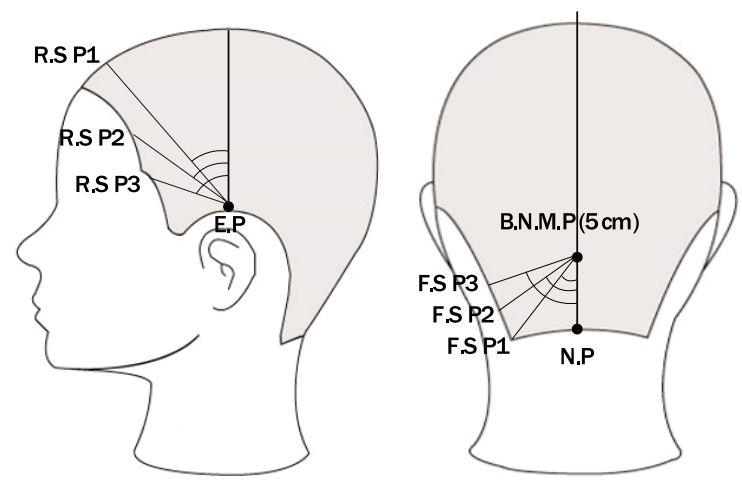

Figure 1. mix of slice lines.

R.S P1, rear slope $40^{\circ}$; R.S P2, rear slope $55^{\circ}$; R.S P3, rear slope $70^{\circ}$; F.S P1, forward slope $40^{\circ}$; F.S P2, forward slope $55^{\circ}$; F.S P3, forward slope $70^{\circ}$; B.N.M.P, back nape medium point; E.P, ear point; N.P, nape point.

각도의 관계에 관한 연구로 남성 헤어커트 교육에 기초자료를 제 공하였다. $\mathrm{A}$ 라인에서 모발길이와 베이스와 각도에 따른 헤어스 타일의 형태 변화를 Jung (2011)이 연구하였으며, Lee (2014)는 Vidal Sassoon, Toni \& Guy, Zone \& Section의 Bob style의 헤 어커트 테크닉을 연구하였다. Kim et al. (2011)은 샤기와 스트록 커트를 얼굴 형태와 두상에 따라 달라지는 이미지에 관해 연구하 여 헤어커트 연구의 다양성을 제시하였다.

최근 헤어 미용 이론의 중요성이 대두됨에 따라 미용의 학문화 와 실기의 기술적인 면에 있어서 객관적 수치화를 위한 연구가 이 루어지고 있으나, 그 수준은 아직도 타 전문분야에 비해 미흡하다 고 할 수 있다(Kwon et al., 2011). 특히 그래주에이션 커트와 커 트형태에 영향을 미치는 요소인 슬라이스 라인의 혼합에 관한 연 구는 그 중요성에 비해 선행연구가 다각도로 이루어지지 않아 실 무와 교육현장에서 필요한 자료가 부족한 실정이다.

따라서 본 연구에서는 그래주에이션 커트에 두상의 뒷면에는 전 경사 슬라이스 라인을 측면에는 후경사 슬라이스 라인을 혼합하여 적용한 후 변화되는 커트형태와 길이변화를 실증하여 커트스타일 의 기초자료를 제공하고자 한다.

\section{Methods}

\section{1. 측정도구 및 방법}

\section{1) 측정도구}

본 연구에 사용된 마네킹 가발은 V사(Venus, Korea)의 27인 치 커트 가발을 사용하였다. 실측을 할 때는 디지털 자(BL-DM; Bluetec, Korea)를 사용하여 길이의 변화를 측정하였다. 시술각 의 각도는 각도계(Starbox, Korea)를 사용하여 베이스(base)의
중간접점에서 측정한 후 헤어커트 하였으며 헤어커트 후에는 약 1 $\mathrm{m}$ 의 일정한 거리에서 디지털 카메라(PL-1; Olympus, China) 를 사용하여 앞모습, 뒷모습, 옆모습을 촬영 후 기록하였다.

커트 도구는 커트 시 일반적으로 사용하는 커트 가위, 커트 빗, 분무기, 클립을 사용하였으며, 마무리는 헤어드라이기를 이용하 여 롤 빗으로 가볍게 모발의 결을 정리하였다.

\section{2) 두상의 분할}

마네킹을 삼각 홀더에 고정한 후 정중선과 측중선으로 나눠서 4 등분 블로킹을 하였다. 이때 정중선은 C.P-N.P (center pointnape point)까지를 연결한 선이며, 측중선은 T.P-E.P (top point-ear point)를 연결한 선을 말한다.

두상 뒷면의 첫 번째 전경사 슬라이스 라인(forward slope slice line, 이하 F.S)은 백 네이프 미디엄 포인트(back nape medium point, 이하 B.N.M.P)를 기점으로 네이프 사이드 포인트(nape side point, 이하 N.S.P)를 연결한 후 이 지점을 F.S1으로 명명하 였다. 이때 전경사 슬라이스 라인의 기울기는 $40^{\circ}$ 였다. 전경사 슬 라이스 라인 두 번째는 B.N.M.P에서 N.S.P 의 $2 \mathrm{~cm}$ 위 지점을 연결하였다. 이것을 F.S2로 명명하였으며, 이때의 기울기는 $55^{\circ}$ 였다. 세 번째는 B.N.M.P에서 N.S.P를 연결한 F.S1 에서 위로 4 $\mathrm{cm}$ 를 연결하였다. 이것을 F.S3으로 명명하였으며, 이때 전경사 의 기울기는 $70^{\circ}$ 였다.

두상의 측면은 후경사 슬라이스 라인(rear slope slice line, 이 하 R.S)을 적용하였다. 측중선을 기점으로 앞쪽으로 뒷면의 전경 사 기울기의 경사각과 같은 각도를 동일하게 적용하였다. 첫 번째 후경사 슬라이스 라인은 측중선과 이어 포인트(ear point, 이하 E.P)에서 기울기 $40^{\circ}$ 를 적용하였으며, 이것을 R.S1으로 명명하 였다. 두 번째는 측중선과 E.P에서 기울기 $55^{\circ}$ 를 적용하여 후경 사 슬라이스 라인을 만들어 R.S2로 명명하였다. 세 번째는 측중 선과 E.P 에서 기울기 약 $70^{\circ}$ 를 적용하여 후경사 슬라이스 라인 을 만들어 R.S3로 명명하였다(Figure 1).

모든 커트 시술은 아래에서 위로 진행하였고, 좌측과 우측을 같 은 방법으로 시술하였다. 각 섹션(section)은 $2 \mathrm{~cm}$ 의 폭으로 일 정하게 나누어 커트하였다.

헤어커트 시 두상의 뒷면 하부의 첫 번째 섹션은 B.N.M.P에서 시작되어 다른 섹션보다 그 폭이 크다. 그러므로 섹션의 폭을 다 른 섹션의 폭과 일관성 있게 맞추기 위해 N.P와 B.N.M.P를 반으 로 2 등분 분할한 후에 각각의 기울기에 맞춰 커트하였다.

\section{3) 측정 방법}

\section{(1) 모발 길이}

커트의 처음 시작되는 길이 가이드(guide)는 N.P 에서 가로, 세 로 $1 \mathrm{~cm}$ 영역의 모발을 취하여 자연 시술각 $0^{\circ}$ 에서 $5 \mathrm{~cm}$ 길이로 설정하였다. 이것은 Jung (2011)의 연구에서 형태선과 볼륨에 따 
른 효과를 확인하기에 가장 적당한 길이이며, 예비 실험에서 얻어 진 결과로 모든 작품의 시술에 동일한 방법으로 가이드를 설정하 여 커트하였다.

\section{(2) 슬라이스 라인}

슬라이스 라인은 두상의 뒷면은 F.S1을 측면은 R.S1을 혼합하였 고, 이것을 MS (mixed slice line, 이하MS)1이라고 명명하였다. 두 번째는 두상의 뒷면F.S2에 측면 R.S2를 혼합 적용하였으며, 이것을 $\mathrm{MS} 2$ 라고 명명하였다. 세 번째는 두상의 뒷면 F.S3에 측면 R.S3를 혼 합 적용하였으며, 이것을 MS3라고 명명하였다.

각각의 그래주에이션 커트에 혼합한 슬라이스 라인 MS1, MS2, $\mathrm{MS} 3$ 를 설정하여 실험에 사용하였다.
(3) 시술각도

혼합한 슬라이스 라인 MS1, MS2, MS3에 그래주에이션 커트 약 $30^{\circ}$, 약 $45^{\circ}$, 약 $70^{\circ}$ 를 각각 대입하여 헤어커트 하였다. 그래주에이션 커트의 시술각도는 NCS의 기초 헤어커트 학습 모듈에서 제시하는 시 술각을 차용하여 로우 그래주에이션 커트는 약 $30^{\circ}$, 미디엄 그래주 에이션은 약 $45^{\circ}$, 하이 그래주에이션은 약 $70^{\circ}$ 로 설정하였다(Kim et al., 2018). 시술각도는 두상 시술 각도를 적용하여 커트하였다.

\section{2. 그래주에이션 커트에서 슬라이스 라인의 혼합에 의한 형태와 길이} 변화

그래주에이션 커트에서 슬라이스 라인의 혼합에 의한 형태변화를 실증하기 위해 두상의 뒷면에 전경사 슬라이스 라인과 측면에 후경사 슬라이스 라인을 혼합하여 적용하였다. 혼합한 슬라이스 라인 MS1,

Table 3. Expanded table on varieties of medium graduation cut according to the mix of slice lines

\begin{tabular}{lcc}
\hline Shape & Medium graduation cut \\
Length & Back & N.P $5 \mathrm{~cm}$ \\
Direction & Side & Forward slope \\
Slice line & Rear slope \\
Base & MS1, MS2, MS3 \\
Angle & Not applicable \\
\hline
\end{tabular}

N.P, nape point; MS, mixed slice line which mixed forward slope line and rear slope line.

Table 4. Results of performing a medium graduation cut with a mix of slice lines

MS1 Medium graduation cut

N.P, nape point; MS, mixed slice line which mixed forward slope line and rear slope line. 
$\mathrm{MS} 2, \mathrm{MS} 3$ 에 그래주에이션 커트 약 $30^{\circ}$, 약 $45^{\circ}$, 약 $70^{\circ}$ 를 각각 대입 하여 헤어커트 하였다.

모든 작품은 헤어커트 전개표(Jung, 2016)를 제시하였다. 헤어커트 를 완성한 작품은 $1 \mathrm{~m}$ 의 거리에서 작품의 앞, 옆, 뒷모습을 사진으로 촬영하여 실증으로 제시 후 형태의 변화를 살펴보았다.

헤어커트의 시작점인 가이드는 길이 $5 \mathrm{~cm}$ 로 설정하였다. 두상의 지점 중에서 center point (이하 C.P), top point (이하 T.P), nape side point (이하 N.S.P), ear point (이하 E.P), back point (이하 B.P), side corner point (이하 S.C.P) 지점을 측정하여 모발길이의 변화를 제시 하였다.

모든 작품은 두상 시술 각도를 적용하였으며 슬라이스 라인에 직각 이 되게 빗질하여 커트하였다. 질감처리는 전혀 하지 않았으며, 블런 트(blunt cut) 커트 후 헤어 드라이기와 롤 빗으로 모발의 결을 가볍게
정리하였다.

\section{Results and Discussion}

\section{1. 슬라이스 라인의 혼합에 따른 로우 그래주에이션 커트}

1) 슬라이스 라인의 혼합에 따른 로우 그래주에이션 커트의 전개표 헤어 커트 전개표는 헤어 커트를 시술하기 전에 시술 방법 및 디자 인을 미리 작성해 보며 계획하는 것으로 시술과정을 미리 체크해 볼 수 있다(Jung, 2016).

두상의 뒷면에 전경사 슬라이스 라인과 측면에 후경사 슬라이스 라 인을 혼합하여 만든 슬라이스 라인 MS1, MS2, MS3에 로우 그래주에

이션 커트의 전개표는 Table 1 과 같다.

\section{Table 5. Expanded table on varieties of high graduation cut according to the mix of slice lines}

\begin{tabular}{lcc}
\hline Shape & High graduation cut \\
Length & Back & N.P $5 \mathrm{~cm}$ \\
Direction & Side & Forward slope \\
Slice line & & Rear slope \\
Base & MS1, MS2, MS3 \\
Angle & Not applicable \\
\hline
\end{tabular}

N.P, nape point; MS, mixed slice line which mixed forward slope line and rear slope line.

Table 6. Results of performing a high graduation cut with a mix of slice lines

MS1 High graduation cut

N.P, nape point; MS, mixed slice line which mixed forward slope line and rear slope line. 
커트의 형태는 로우 그래주에이션으로 분류되며, 가이드(guide)는 N.P $5 \mathrm{~cm}$ 를 적용할 것임을 나타낸다. 커트의 방향은 뒷면은 전경사, 측면은 후경사를 대입할 것이며, 슬라이스 라인은 혼합하여 만든MS1, $\mathrm{MS} 2, \mathrm{MS} 3$ 커트할 것임을 나타낸다. 베이스는 해당사항이 없는데, 이 는 빗질 방향을 슬라이스 라인에 대해서 직각으로 빗어서 커트할 것이 기 때문이다. 두상시술각도 약 $30^{\circ}$ 의 시술각도를 사용하여 헤어커트 할 것임을 계획한 것이다.

\section{2) 슬라이스 라인의 혼합에 따른 로우 그래주에이션 커트의 시술 결과}

전경사 경사각이 $40^{\circ}$, 후경사 경사각이 $40^{\circ}$ 인 $\mathrm{MS} 1$, 전경사 경사각이 $55^{\circ}$, 후경사 경사각이 $55^{\circ}$ 인 $\mathrm{MS} 2$, 전경사 경사각이 $70^{\circ}$, 후경사 경사각 이 $70^{\circ}$ 인 MS3를 두상시술각도 약 $30^{\circ}$ 의 로우 그래주에이션 커트에 대 입하여 헤어커트한 결과는 Table 2에 나타냈다.

앞모습은 같은 시술각도임에도 혼합 슬라이스 라인 경사각의 변화에 따라서 길이가 달라지며, MS1보다 MS3에서 길이가 짧아지며 형태가 무겁게 나타났다.

옆모습은 혼합 슬라이스 라인의 기울기에 따라서 길이차이가 현저하 게 달라지며 형태선이 변화되는 것을 볼 수 있다. 뒷면의 전경사와 측면 의 후경사 경사각이 서로 만나서 예각이 된 상태가 헤어커트에 그대로 반영되어 $\mathrm{MS} 1$ 은 $\mathrm{V}$ 자 모양의 볼록한 형태선이 가장 도드라지게 나타났 다.

뒷모습은 뒷면 전경사 슬라이스 라인의 기울기에 따라서 형태선에 변 화가 나타나며 MS1에서 오목한 형태선이 두드러졌다.

두상의 뒷면과 측면에 동일한 경사각의 슬라이스 라인을 사용한 결과 측중선을 기점으로 양쪽에 동일한 형태선이 나타난 것을 볼 수 있다. 이 러한 결과는 슬라이스 라인을 혼합하여 새로운 커트디자인이 가능하다 는 것을 나타낸다. 그리고 경사선의 기울기 만으로도 커트디자인의 형태 에 변화를 줄 수 있다는 Moon \& Jung (2018)의 연구와도 유사한 결과이 다.

\section{2. 슬라이스 라인의 혼합에 따른 미디엄 그래주에이션 커트}

1) 슬라이스 라인의 혼합에 따른 미디엄 그래주에이션 커트의 전개표
전경사 슬라이스 라인과 후경사 슬라이스 라인을 혼합하여 만든 슬라이스 라인 MS1, MS2, MS3에 미디엄 그래주에이션 커트의 전 개표는 Table 3 과 같다

커트의 형태는 미디엄 그래주에이션 커트로 분류되며, 가이드는 N.P $5 \mathrm{~cm}$ 를 적용할 것임을 나타낸다. 커트의 방향은 뒷면은 전경 사, 측면은 후경사를 대입할 것이며, 슬라이스 라인은 혼합하여 만 든 $\mathrm{MS} 1, \mathrm{MS} 2, \mathrm{MS} 3$ 커트할 것임을 나타낸다. 베이스는 슬라이스 라인에 대해서 직각으로 빗고 각도를 적용할 것이므로 해당사항이 없다. 두상시술각도 약 $45^{\circ}$ 를 사용하여 헤어커트 할 것임을 나타낸 다.

이와 같은 전개표는 커트디자인을 설계하는 것으로 디자인계획 단계에서 필요한 시술방법과 과정을 미리 구상할 수 있는 절차이다 (Jung, 2016).

2) 슬라이스 라인의 혼합에 따른 미디엄 그래주에이션 커트의 시술 결과

전경사 슬라이스 라인과 후경사 슬라이스 라인을 혼합하여 만든 슬라이스 라인 MS1, MS2, MS3에 두상 시술각도 약 $45^{\circ}$ 의 미디엄 그래주에이션 커트를 한 결과는 Table 4에 나타냈다.

앞모습의 경우 뒷면 전경사 슬라이스 라인의 기울기에 따라서 길 이 변화와 함께 형태선의 변화가 나타났다. 모발 끝의 겹쳐짐이 두 상의 곡면으로 인해 자연스럽게 안쪽으로 말아 들어가는 현상이 나 타났다.

옆모습에서는 측중선을 중심으로 혼합 슬라이스 라인의 경사각 에 따라서 커트스타일의 형태선에 그대로 반영되는 결과를 보였다. 그 결과로 $\mathrm{MS} 1$ 의 형태선이 가장 뚜렷하게 $\mathrm{V}$ 의 볼록한 형태선을 나 타내고 MS2, MS3로 갈수록 형태선이 U라인으로 완만해지는 것을 볼 수 있다.

뒷모습은 전경사 슬라이스 라인 기울기에 따라서 형태선에 변화 가 나타났다.

앞모습과 옆모습은 측면의 후경사 슬라이스 라인으로 인해 형태 선이 두상을 따라서 둥글게 돌아가며 형성되었는데, 이것은 Jung

Table 7. Changes in lengths based on the mix of forward and rear slope slice lines in graduation haircuts

\begin{tabular}{|c|c|c|c|c|c|c|c|c|}
\hline & & N.P & N.S.P & E.P & S.C.P & B.P & T.P & C.P \\
\hline \multirow{3}{*}{ Low graduation cut } & MS1 & 5.0 & 7.5 & 19.0 & 15.0 & 12.3 & 22.5 & 15.5 \\
\hline & MS2 & 5.0 & 6.5 & 14.5 & 13.0 & 12.3 & 22.5 & 16.2 \\
\hline & MS3 & 5.0 & 5.4 & 12.5 & 11.5 & 12.3 & 23.0 & 16.8 \\
\hline \multirow{3}{*}{ Medium graduation cut } & MS1 & 5.0 & 7.5 & 15.7 & 13.0 & 11.0 & 19.0 & 12.0 \\
\hline & MS2 & 5.0 & 6.4 & 14.0 & 12.0 & 11.2 & 19.0 & 13.0 \\
\hline & MS3 & 5.0 & 5.5 & 12.0 & 11.0 & 11.2 & 19.0 & 14.2 \\
\hline \multirow{3}{*}{ High graduation cut } & MS1 & 5.0 & 6.2 & 12.2 & 9.5 & 8.2 & 12.5 & 8.0 \\
\hline & MS2 & 5.0 & 5.5 & 11.1 & 9.0 & 8.2 & 12.5 & 9.2 \\
\hline & MS3 & 5.0 & 5.3 & 9.5 & 8.5 & 8.0 & 12.7 & 10.0 \\
\hline
\end{tabular}

N.P, nape point; N.S.P, nape side point; E.P, ear point; S.C.P, side corner point; B.P, back point; T.P, top point; C.P, center point; MS, mixed slice line which mixed forward slope line and rear slope line. 
\& Youn (2015)이 보고한 슬라이스 V라인에서 입체감이 두상을 따 라 돌아가며 둥글고 또렷하게 형성되었다는 결과와 같다.

\section{3. 슬라이스 라인의 혼합에 따른 하이 그래주에이션 커트}

1) 슬라이스 라인의 혼합에 따른 하이 그래주에이션 커트의 전개표

혼합하여 만든 슬라이스 라인 MS1, MS2, MS3에 하이 그래주에 이션 커트의 전개표는 Table 5 와 같다.

형태는 하이 그래주에이션 커트 형태에 해당되며, 가이드는 N.P $5 \mathrm{~cm}$ 를 적용하여 커트할 것임을 나타낸다. 커트방향은 슬라이스 라인에 직각으로 빗질하여 커트하므로 뒷면은 전경사, 측면은 후경 사로 커트할 것임을 나타낸다. 슬라이스 라인은 혼합하여 만든 슬라 이스 라인 MS1, MS2, MS3를 대입하여 커트할 것임을 나타낸다. 베이스는 해당사항이 없으며, 약 $70^{\circ}$ 의 두상시술각도를 사용하여 헤어커트 할 것임을 계획한 것이다.

2) 슬라이스 라인의 혼합에 따른 하이 그래주에이션 커트의 시술결과 혼합 슬라이스 라인 MS1, MS2, MS3에 하이 그래주에이션 커트 를 시술한 결과는 Table 6 과 같다.

앞모습은 비교적 높은 시술각도와 후경사 슬라이스 라인에 따른 형태변화가 나타났다.

옆모습은 혼합 슬라이스 라인의 경사각에 따라서 형태선의 변화 가 나타났다. 하이 그래주에이션의 영향으로 모발 길이가 짧아져서 E.P를 연결하는 형태선의 높이가 로우나 미디엄 그래주에이션 커트 보다 올라갔다. 두상에서 위로 갈수록 길어지는 그래주에이션의 형 태는 있으나, 높은 시술각도로 인한 가벼운 느낌이 강하며 약간의 무게감과 입체감을 볼 수 있다.

뒷모습은 로우나 미디움 그래주에이션 커트에 비해 가벼운 실루 엣을 보였다.

\section{4. 그래주에이션 커트의 전경사와 후경사 슬라이스 라인의 혼합에 따른 길이변화}

혼합한 슬라이스 라인 MS1, MS2, MS3에 로우 그래주에이션 커 트, 미디엄 그래주에이션 커트, 하이 그래주에이션을 각각 대입하여 커트한 후 각 지점의 길이를 측정한 결과는 Table 7과 같다.

가이드 길이 $5 \mathrm{~cm}$ 로 커트를 시작한 로우 그래주에이션 커트는 S.C.P의 길이가 MS1은 $15.0 \mathrm{~cm}, \mathrm{MS} 2$ 는 $13.0 \mathrm{~cm}, \mathrm{MS} 3$ 는 11.5 $\mathrm{cm}$ 로 MS3으로 갈수록 측정된 길이가 점점 짧아졌다. 이것은 S.C.P가 E.P보다 아래에 위치한 영향 때문이다. C.P 지점에서는 $\mathrm{MS} 115.5 \mathrm{~cm}, \mathrm{MS} 216.2 \mathrm{~cm}, \mathrm{MS} 316.8 \mathrm{~cm}$ 로 MS3로 갈수록 길 이가 길어졌다. 이는 후경사 슬라이스 라인의 경사도가 낮아짐에 의 한 결과이다.

가이드 길이 $5 \mathrm{~cm}$ 로 커트를 시작한 미디엄 그래주에이션 커트는 S.C.P의 길이가 MS1 $13.0 \mathrm{~cm}, \mathrm{MS} 212.0 \mathrm{~cm}, \mathrm{MS} 311.0 \mathrm{~cm}$ 로 실 측 되었다. C.P의 길이는 MS1 $12.0 \mathrm{~cm}, \mathrm{MS} 213.0 \mathrm{~cm}, \mathrm{MS} 314.2$ $\mathrm{cm}$ 로 MS3으로 갈수록 길이가 길어 졌다. 이 또한 로우 그래주에이 션 커트와 같이 측면의 후경사 슬라이스 라인 경사도가 낮아짐에 의 한 영향이다.

가이드 길이 $5 \mathrm{~cm}$ 로 커트를 시작한 하이 그래주에이션 커트는 S.C.P의 길이가 MS1 $9.5 \mathrm{~cm}$, MS2 $9.0 \mathrm{~cm}$, MS3 $8.5 \mathrm{~cm}$ 로 나타 났다. C.P의 길이는 MS1 $8.0 \mathrm{~cm}, \mathrm{MS} 29.2 \mathrm{~cm}$, MS3 $10.0 \mathrm{~cm}$ 로 나타났다.

이는 슬라이스 라인 기울기의 경사도가 길이 변화와 함께 형태선 에 영향을 미치므로 커트디자인에 활용할 수 있다는 것을 나타낸다. 그러므로 커트 디자인을 할 때 형태선과 실루엣을 결정하는 요인으 로 슬라이스 라인과 슬라이스 라인의 경사선 기울기를 활용하는 것 이 용이하다는 Moon \& Jung (2018)의 연구와도 유사한 것이다.

\section{Conclusion}

그래주에이션 커트에 두상의 뒷면에는 전경사 슬라이스 라인을 측면에는 후경사 슬라이스 라인을 혼합하여 적용한 후 변화되는 커 트형태와 길이변화를 실증하여 커트스타일의 기초자료를 제공하고 자 연구한 결과 다음과 같은 결론을 얻었다.

첫째, 두상의 뒷면에 전경사 슬라이스 라인과 측면에 후경사 슬 라이스 라인을 혼합한 결과 슬라이스 라인의 경사각에 따라서 길이 와 형태선에 변화가 나타났다. 이것은 슬라이스 라인 혼합에 의하 여 만들어진 경사각이 커트 형태선에 영향을 주므로 커트디자인을 할 때 슬라이스 라인의 혼합은 물론 그 경사도에 따라서도 여러 가 지 커트스타일을 만들어 낼 수 있을 것으로 사료된다.

둘째, 미디엄 그래주에이션 커트의 슬라이스 라인 혼합에서 볼륨 에 의한 입체감이 가장 크게 나타났다. 또한 미디엄 그래주에이션 커트에서 측면의 모발들이 안쪽으로 말려들어가는 안말음 현상이 두드러지게 나타났다. 이는 측면의 후경사 슬라이스 라인과 시술각 도에 의한 층이 얼굴의 곡선을 타고 내려가다가 안쪽으로 말려들어 가는 현상을 증가시킨 것으로 사료된다.

셋째, 하이 그래주에이션 커트의 경우 입체감과 볼륨감은 로우나 미디엄 그래주에이션 커트보다 다소 적으나, N.S.P와 S.C.P, C.P 를 연결하는 헴 라인(hem line)과 슬라이스 라인의 혼합으로 인해 나타난 형태선은 커트디자인의 다양성을 표현하기에 적절하다고 사료된다.

이로써 그래주에이션 커트에 다양한 기울기의 전경사 슬라이스 라인과 후경사 슬라이스 라인을 혼합하여 적용한 후 변화되는 커트 형태와 길이변화를 실증하여 커트스타일의 기초 자료를 제공하였 다. 그래주에이션 커트에서 혼합한 슬라이스 라인의 경사도를 이용 하여 두상의 함몰이나 밋밋함을 보완하고자 하는 볼륨과 입체감을 부여할 수 있다. 더불어 커트디자인에 맞는 원하는 길이를 조절하 기에 용이할 것으로 판단된다. 또한 측면에 후경사 슬라이스 라인 
의 경사도를 이용한 커트디자인은 얼굴형의 단점을 보완하기에 적 당하며, 앞쪽에서 보이는 페이스 라인(face line)의 모발들을 이용 한 다양한 커트스타일이 가능할 것으로 사료된다.

본 연구로 인해 커트디자인을 할 때에 하나의 슬라이스 라인을 적용하는 것보다는 혼합한 슬라이스 라인을 적용하여 좀 더 다양 한 커트스타일을 만들어 낼 수 있다는 것을 실증하였다. 그리고 커 트디자인을 도식화한다면 좀 더 빠른 이해와 시술을 할 수 있을 것 으로 사료된다. 향후 연구에서는 기초 헤어커트의 혼합으로 나타날 수 있는 다양한 커트스타일과 트렌디 한 커트스타일에 관한 연구가 함께 이루어져야 할 것이다.

\section{References}

Han JS, Youn CS. A study on analysis of hair cut line based on the pythagorean theorem: focused on overdirection. Journal of Beauty Industry, 2: 53-74, 2007.

Hong SH, Joo YB. 7-Section \& zone for scalp division used in cutting hair. Journal of the Korean Society of Beauty and Art, 16: 203-211, 2015.

Ha SK, Youn CS. A study on the Korean style hair cut method. Journal of the Korean Society of Cosmetology, 23: 1002-1014, 2017.

Jung WJ. Form change of hair style in relation with hair length, base, and angle in a-line hair-cut. Journal of Investigative Cosmetology, 7: 197-205, 2011.

Jung WJ, Youn CS. Factors of form change by hair-cut. Journal of the Korean Society of Cosmetology, 14: 893899, 2008.

Jung WJ, Youn CS. Form change in parallel line hair cut: focusing on the hair length, angle, base. Journal of Beauty Industry, 8: 65-78, 2014.

Jung WJ, Youn CS. Form change of cut style in relation with hair length, angle and base. Journal of Beauty Industry, 9: 53-68, 2015.

Jung WJ. An empirical study of the graduation cut on the basic haircut. Journal of Beauty Industry, 10: 47-61, 2016.

Jung WJ, Kim Cl. An empirical study on the mixed style of isadora bob cut and graduation cut. Journal of Beauty Industry, 11: 37-53, 2017.
Kim GO, Han HS, Hwang WG. A study on the shaggy \& stroke cut hairstyles according to facial appearances and head shapes. Asian Journal of Beauty and Cosmetology, 9: 1-12, 2011.

Kim SM. A study on the cultural history of hair cut. Journal of the International Society of Nail Beauty Design, 5: 4752, 2017.

Kim SH. A study on form changes of hair styles after adjustment in hair cut section line and combination position: focusing on graduation haircut and increase layer haircut. Journal of the Korean Society of Cosmetology, 21: 1173-1181, 2015.

Kim SH. A study on hair style changes by changes in the volume of hair cut blocks, hair length and section line in hair cut: focusing on one length cut and increase layered cut. Journal of the Korean Society of Cosmetology, 22: 1341-1351, 2016.

Kim JS, Kang JA, Goh SH, Gwak HS, Kwon EJ, Kim MJ, Kim SW, Kim OG, Kim TY, Kim HT, et al. Basic haircut. Krivet, Sejong, pp64-109, 2018.

Kim HM, Lee JS. A study on the male hair cut section division. Journal of the Korean Society of Cosmetology, 23: 811-823, 2017.

Kwon HJ, Kim TS, Jin YM. A study on hair design based on principle of proportion and texture technique. Journal of Beauty Art Management, 5: 127-142, 2011.

Lee OK. The comparative analysis of bob style, according to each foreign brand's haircut diagram, mainly vidal sassoon, toni \& guy and zone \& section. Asian Journal of Beauty and Cosmetology, 12: 607-612, 2014.

Moon SJ, Jung WJ. Changes in form line and length in accordance with inclination of slice line in one-length cut. Journal of the Korean Society of Cosmetology, 24: 743-751, 2018.

Park SK, Seo YK. A study on hair design avail of section's change. Journal of the Korean Society of Beauty and Art, 10: 127-138, 2009.

Song YN, Cho JH. A study on angles connecting the side head and the back head in man's crew cut. Journal of the Korean Society of Cosmetology, 18: 305-309, 2012. 


\section{국문초록}

\section{그래주에이션 커트에 전경사와 후경사 슬라이스 라인의 혼합에 따른 형태변화}

장선미, 정원지

광주여자대학교 미용과학과, 광주, 한국

목적: 그래주에이션 커트에 두상의 뒷면에는 전경사 슬라이스 라인을 측면에는 후경사 슬라이스 라인을 혼합하여 적용한 후 변화 되는 커트형태와 길이변화를 실증하여 커트스타일의 기초자료를 제공하고자 한다. 방법: 마네킹에 약 $30^{\circ}$ 의 로우 그래주에이션 커 트, 약 $45^{\circ}$ 의 미디엄 그래주에이션 커트, 약 $70^{\circ}$ 의 하이 그래주에이션 커트에 전경사와 후경사를 혼합한 슬라이스 라인 MS1 $\left(40^{\circ}\right)$, $\operatorname{MS} 2\left(55^{\circ}\right)$, MS3 $\left(70^{\circ}\right)$ 를 각각 대입하여 커트하였다. 결과: 그래주에이션 커트 시 혼합한 슬라이스 라인에 따라서 다양한 형태선이 나타났다. 미디엄 그래주에이션 커트의 MS1을 적용한 헤어커트가 가장 효과적인 입체감이 있는 것으로 나타났다. 결론: 그래주에 이션 커트를 할 때 혼합된 슬라이스 라인에 의해 커트스타일의 형태선과 형태 변화가 가능하다는 것이 실증되었다. 이로써 전경사 슬라이스 라인과 후경사 슬라이스 라인의 혼합을 이용한 다양한 커트디자인이 가능할 것으로 사료된다.

핵심어: 그래주에이션 커트, 후경사 슬라이스라인, 전경사 슬라이스 라인, 헤어커트, 혼합 슬라이스 라인

\section{참고문헌}

김경옥, 한효선, 황완균. 얼굴 형태와 두상에 따른 샤기와 스트록 커트에 관한 연구. 아시안뷰티화장품학술지, 9: 1-12, 2011.

김수민. 헤어미용커트문화사연구. 한국네일미용학회지, 5: 47-52, 2017.

김순희. 헤어 커트의 섹션라인과 혼합위치의 변화에 따른 헤어스타일의 형태변화에 관한 연구: 그래쥬에이션 커트와 인크 리스 레이어 커트 혼합을 중심으로. 한국미용학회지, 21: 1173-1181, 2015.

김순희. 헤어커트에 있어서 커트 블럭의 량과 모발의 길이, 섹션 라인의 변화에 따른 헤어스타일의 형태 변화에 관한 연구:

원랭스 커트와 인크리스 레이어 커트를 중심으로. 한국미용학회지, 22: 1341-1351, 2016.

김진숙, 강주아, 고성현, 곽형심, 권은경, 김민정, 김서원, 김옥기, 김태영, 김현태 외. 기초 헤어 커트. 한국직업능력개발 원, 세종시, pp64-109, 2018.

김혜민, 이재숙. 남성 헤어커트 섹션 분할 연구. 한국미용학회지, 23: 811-823, 2017. 권혜지, 김태숙, 진용미. 비례의 원리와 질감 테크닉을 응용한 헤어디자인 연구. 미용예술경영연구, 5: 127-142, 2011. 문승재, 정원지. 원랭스 커트 시 슬라이스라인 기울기에 따른 형태선과 길이변화. 한국미용학회지, 24: 743-751, 2018. 박상국, 서윤경. 섹션의 변화를 활용한 헤어디자인 연구. 한국인체미용예술학회지, 10: 127-138, 2009. 송유나, 조지훈. 상고 유형의 남성헤어커트 에서 연결 각도의 관계 연구. 한국미용학회지, 18: 305-309, 2012 이옥규. Vidal Sassoon, Toni \& Guy, Zone \& Section 중심으로 해외브랜드별 헤어 커트 도해도에 따른 Bob Style의 비 교분석. 아시안뷰티화장품학술지, 12: 607-612, 2014.

정원지. 헤어커트 시 A라인에서 모발길이와 베이스와 각도에 따른 헤어스타일의 형태변화. 대한미용학회지, 7: 197-205, 2011.

정원지. 윤천성. 헤어커트의 形態에 變化를 주는 要因에 관한 연구. 한국미용학회지, 14: 893-899, 2008

정원지, 윤천성. 헤어커트 시 평행선(Parallel Line)에서의 형태변화: 모발길이, 시술각도, 베이스를 중심으로. 뷰티산업연 구, 8: 65-78, 2014.

정원지, 윤천성. 헤어 커트를 할 때 $\mathrm{V}$ 라인에서 모발길이와 각도와 베이스에 따른 커트스타일의 형태변화. 뷰티산업연구, 9: 53-68, 2015. 
정원지. 기본헤어커트에서 그래쥬에이션 커트의 실증연구. 뷰티산업연구, 10: 47-61, 2016.

정원지, 김춘일. 이사도라 보브형 커트와 그래쥬에이션 커트의 혼합형스타일에 대한 실증연구. 뷰티산업연구, $11: 37-53$, 2017.

하성기, 윤천성. 한국형 헤어 커트 방법 연구. 한국미용학회지, 23: 1002-1014, 2017.

한지승, 윤천성. 피타고라스의 정리를 이용한 헤어컷 라인분석: 오버다이렉션(Overdirection)을 중심으로. 뷰티산업연구, 2: 53-74, 2007.

홍성희, 주연빈, 헤어 커트에 사용되는 두상 분할에 대한 7섹션 존 연구. 한국인체미용술학회지, 16: 203-211, 2015. 


\section{中文摘要}

\section{斜率刻度剪发中混合前后倾斜线引起的形态变化}

張先美，鄭圓至

光州女子大学美容科学科, 光州市, 韩国

目的: 本研究旨在通过结合头部后部的前倾斜切线和头部两侧的后倾斜切线来演示样式和头发长度的变化来提供 理发样式的基本数据。方法: 实验者通过应用切片线MS1 $\left(40^{\circ}\right)$ ，MS2 $\left(55^{\circ}\right)$ 和MS3 $\left(70^{\circ}\right)$ 切割人体模型的 头发, 用于约 $30^{\circ}$ 的低刻度切割, 约 $45^{\circ}$ 的中等刻度切割, 以及高分度约为 $70^{\circ}$ 。结果: 根据切割中混合的切片线 出现各种形状线。使用MS1的理发风格结合中等刻度切割发型产生最有效的三维效果。结论: 结果表明，与刻度 切割相结合的切片线可用于改变理发样式的形状线条和形状。这些结果表明，通过使用前后斜切片线的混合， 可以创建各种理发设计。

关键词: 刻度切割, 后倾斜切线, 前倾斜切线, 剪发, 混合切片线 
